\title{
BMJ Open Paediatric ED BiPAP continuous quality improvement programme with patient analysis: $2005-2013$
}

Thomas Abramo, ${ }^{1,2}$ Abby Williams,, ${ }^{3,4}$ Samaiya Mushtaq, ${ }^{3,5}$ Mark Meredith,, ${ }^{1,6}$ Rawle Sepaule, ${ }^{7}$ Kristen Crossman, ${ }^{1}$ Cheryl Burney Jones, ${ }^{8}$ Suzanne Godbold, ${ }^{9}$ Zhuopei Hu, ${ }^{8}$ Todd Nick ${ }^{8}$

To cite: Abramo T,

Williams A, Mushtaq S, et al. Paediatric ED BiPAP continuous quality improvement programme with patient analysis: 20052013. BMJ Open 2017;7: e011845. doi:10.1136/ bmjopen-2016-011845

- Prepublication history and additional material is available. To view please visit the journal (http://dx.doi.org/ 10.1136/bmjopen-2016011845).

Received 14 March 2016 Revised 5 October 2016 Accepted 10 November 2016

CrossMark

For numbered affiliations see end of article.

Correspondence to Dr Thomas Abramo; tjabramo@uams.edu

\section{ABSTRACT}

Objective: In paediatric moderate-to-severe asthmatics, there is significant bronchospasm, airway obstruction, air trapping causing severe hyperinflation with more positive intraplural pressure preventing passive air movement. These effects cause an increased respiratory rate (RR), less airflow and shortened inspiratory breath time. In certain asthmatics, aerosols are ineffective due to their inadequate ventilation. Bilevel positive airway pressure (BiPAP) in acute paediatric asthmatics can be an effective treatment. BiPAP works by unloading fatigued inspiratory muscles, a direct bronchodilation effect, offsetting intrinsic PEEP and recruiting collapsed alveoli that reduces the patient's work of breathing and achieves their total lung capacity quicker.

Unfortunately, paediatric emergency department (PED) BiPAP is underused and quality analysis is nonexistent. A PED BiPAP Continuous Quality Improvement Program (CQIP) from 2005 to 2013 was evaluated using descriptive analytics for the primary outcomes of usage, safety, BiPAP settings,

therapeutics and patient disposition.

Interventions: PED BiPAP CQIP descriptive analytics. Setting: Academic PED.

Participants: 1157 patients.

Interventions: A PED BiPAP CQIP from 2005 to 2013 for the usage, safety, BiPAP settings, therapeutic response parameters and patient disposition was evaluated using descriptive analytics.

Primary and secondary outcomes: Safety, usage, compliance, therapeutic response parameters, BiPAP settings and patient disposition.

Results: 1157 patients had excellent compliance without complications. Only $6(0.5 \%)$ BiPAP patients were intubated. BiPAP median settings: IPAP $18(16,20)$ $\mathrm{cm} \mathrm{H}_{2} \mathrm{O}$ range 12-28; EPAP $8 \mathrm{cmH}_{2} \mathrm{O}(8,8)$ range 6-10; inspiratory-to-expiratory time (I:E) ratio $1.75(1.5,1.75)$. Pediatric Asthma Severity score and RR decreased $(p<0.001)$ while tidal volume increased $(p<0.001)$. Patient disposition: 325 paediatric intensive care units (PICU), 832 wards, with 52 of these PED ward patients were discharged home with only 2 hours of PED BiPAP with no returning to the PED within 72 hours.

Conclusions: BiPAP is a safe and effective therapeutic option for paediatric patients with asthma presenting to

\section{Strengths and limitations of this study}

- There is limited evidence-based alternative interventions available for paediatric emergency department (PED) moderate-to-severe status asthmatic non-responders, but there is an increasing clinical practice trend for using pressure-driven aerosol delivery system like bilevel positive airway pressure (BiPAP) as an alternative therapy.

- Analysis of an 8-year moderate or severe asthmatics PED BiPAP Continuous Quality Improvement Program (CQIP) showed it was safe, no expected nor unexpected complications, well tolerated by all ages and no worsening or decompensation occurred from BiPAP therapy (only 6 patients required intubation out of 1157 patients).

- PED BiPAP Asthma CQIP analysis showed the optimal BiPAP IPAP, EPEP and inspiratoryto-expiratory time (I:E) settings for various ages.

- With the optimal BiPAP settings (increasing IPAP, lower EPAP and longer I:E ratio) there were significant improvements in their Pediatric Asthma Severity score, decrease intubations, decrease paediatric intensive care unit admissions and shorter PED BiPAP duration time.

- In BiPAP patients with PED discontinuation, none had BiPAP reinitiated, a subset of these PED patients were sent home with no PED return visit within next 7 days.

- This study is not an asthmatic BiPAP random control trial (between non-BiPAP and the BiPAP patients) but an analysis of an 8-year continuous PED asthmatic BiPAP quality improvement programme with inherent associated bias (PED attending and staff practice variation changes, long PED BiPAP duration times due to limited bed availability, increasing earlier BiPAP application due to its acceptance, comfort level and ease of application).

a PED or emergency department. This BiPAP CQIP showed significant patient compliance, no complications, improved therapeutics times, very low intubations and decreased PICU admissions. CQIP analysis demonstrated that using a higher IPAP, Iow EPAP with longer I:E optimises the patient's BiPAP 
settings and showed a significant improvement in PAS, RR and tidal volume. BiPAP should be considered as an early treatment in the PED severe or non-responsive moderate asthmatics.

\section{INTRODUCTION}

An increasing percentage of paediatric patients with status asthmaticus require adjunct asthma therapy (different $\beta$-2 agonist agents, pressure-driven aerosols delivery systems (positive airway pressure (CPAP) or bilevel positive airway pressure (BiPAP)), intravenous (IV) magnesium sulfate, systemic $\beta$-2 agonist), in the paediatric emergency department (PED) ${ }^{1-3}$ These patients have increased inspiratory and expiratory airway obstruction producing significant dynamic hyperinflation and ineffective ventilation causing an increasing inspiratory work of breathing resulting in inspiratory muscle fatigue. ${ }^{4-6}$ In recent paediatric asthma trials, ventilation heterogeneity and individualistic $\beta-2$ receptor response to medications have been proposed as the aetiology of patient's variable response to bronchodilator therapy. ${ }^{7-9}$ Current aerosol systems can be ineffective in certain asthmatics with large airway obstruction and poor lung ventilation while CPAP or BiPAP has shown to be beneficial in these asthmatics. $^{10-14}$ In acute asthmatics, BiPAP has a direct bronchodilator effect, achieves greater peripheral bronchodilator dispersal while unloading fatigued inspiratory muscles, offsetting auto positive end-expiratory pressure (auto-PEEP), recruiting collapsed alveoli all causing a reduction in their work of breathing and achieving their total lung capacity quicker. ${ }^{11-15}$

BiPAP/CPAP therapy for asthma and chronic obstructive pulmonary disease in adults in the emergency department (ED) has been shown to safely reduce ED length of stay (LOS), hospitalisation rates, and intensive care unit (ICU) admissions. ${ }^{9-14}$ PED BiPAP use in patients with asthma, has demonstrated safety, reduced ICU admissions and decreased hospital LOS. ${ }^{15-20}$ BiPAP has become a standard therapy in the paediatric intensive care units (PICU) but rarely reported in the PED. ${ }^{15-21}$ Potential PED BiPAP barriers to use in the PED include a lack of paediatric BiPAP knowledge/practice comfort level, difficult to implement the PED, BiPAP mask selection (Which one is appropriate: nasal, oral nasal mask or full face mask?) and aerosol setup (Where to place the continuous aerosol in BiPAP system: just before the mask or at the machine end?), worsening the patient's asthma severity by increasing the auto-PEEP, causing increase stomach distension with increase vomiting and increasing patients hospital LOS and PCIU admission by a recent report. A more relevant PED BiPAP barriers are few PED BiPAP random control trial (RCT) studies, unknown acute asthmatic BiPAP standardised settings and a robust BiPAP patient quality analysis reporting. Another major misconception is that PED BiPAP would prolong the patient's asthma attack duration, increase the PED LOS and overall PED patient LOS. $^{5}$ A clinical practice trend of using high flow nasal cannula (HFNC) instead of BiPAP usage practice trend has been occurring, which current HFNC systems cannot deliver aerosolised $\beta-2$ agonist agents, in these poorly responding ED moderate-to-severe asthmatics after routine therapy. A recent extensive PubMed/Ovid literature review demonstrated no HFNC published RCT for its use in acute asthma. The limited PED BiPAP safety and no PED BiPAP quality literature may have led to this current practice trend.

In 2005 on initiation of PED BiPAP therapy in asthma or other diseases, a PED BiPAP Continuous Quality Improvement Program (CQIP) was developed, and continued through 2013. The objective of this study was to describe a PED BiPAP database and CQIP along with patient's clinical trends and descriptive analysis in 1157 BiPAP-treated moderate or severe asthmatics from 2005 to 2013.

\section{METHODS}

Vanderbilt Children's Hospital PED is a level I PED with 56000 annual patient visits and 2970 on average paediatric asthma visits per year from 2005 to 2013. A Pediatric Asthma Severity (PAS) score was used and recorded by the PED staff (physicians, nurses and respiratory therapist (RT)) from 2005 to 2008. From 2009 to 2013, an individualised component input-derived PAS score was used by the triage nurse, RT, nurses and physicians for initial assessment, and to drive asthma therapeutic interventions $^{101819}$ (table 1 ).

A further refinement of the PED standard PAS asthma assessment times were developed by the primary investigators to accommodate the PED asthmatic BiPAP therapy application and as a BiPAP CQIP metric. The BiPAP CQIP PAS assessment times were selected by the primary investigators in 2005-2008 as the following: at triage, just before BiPAP placement, at 4 hours of BiPAP (taken off for $15 \mathrm{~min}$ PAS assessed) or at the 4 hours of BiPAP with discontinuation of BiPAP. In 2009, the investigators change the PAS assessment times since the increasing number of patient's BiPAP duration were decreasing from 4 to 2-4 hours. The investigators change the final BiPAP PAS to reflect the changes or variation in PED BiPAP duration times. The final PAS was changed to $30 \mathrm{~min}$ after BiPAP discontinuation or at 4 hours of PED BiPAP whether continued or not.

Beginning in 2005, a BiPAP CQIP was developed and continued through 2013. The PED RT and the study investigators recorded these BiPAP CQI metrics into the BiPAP CQIP Research Electronic Data Capture (REDCap) description and online supplementary material 1. PED BiPAP metrics for the BiPAP CQIP process was collected retrospectively from 2005 to 2006 by one of the investigators with more limited CQIP metric indicators (asthma diagnosis in the PED patients or general electronic medical record (EMR), aerosol use, steroids, admission placement and or rapid response or later PICU transfer, PED intubations, PICU intubations, 
Table 1 PAS score

\begin{tabular}{|c|c|c|c|c|}
\hline PAS & 0 & 1 & 2 & 3 \\
\hline \multicolumn{5}{|c|}{ Respiratory rate } \\
\hline $\begin{array}{l}6 \text { months- } \\
2 \text { years }\end{array}$ & $\leq 30$ & $31-45$ & $46-60$ & $\geq 60$ \\
\hline $2-3$ years & $18-26$ & $27-34$ & $35-39$ & $\geq 40$ \\
\hline $4-5$ years & $16-24$ & $25-30$ & $31-35$ & $\geq 36$ \\
\hline $6-12$ years & $14-20$ & $21-26$ & $27-30$ & $\geq 31$ \\
\hline$>12$ years & $12-18$ & 19-23 & $24-27$ & $\geq 28$ \\
\hline $\begin{array}{l}\text { Oxygen } \\
\text { saturation }\end{array}$ & $\geq 98 \%$ on room air & $95-97 \%$ on room air & $\begin{array}{l}90-94 \% \text { on room } \\
\text { air }\end{array}$ & $\begin{array}{l}\leq 90 \% \text { on room air OR on any } \\
\text { supplemental oxygen }\end{array}$ \\
\hline Auscultation & $\begin{array}{l}\text { Normal breath sounds } \\
\text { with good aeration } \\
\text { throughout }\end{array}$ & $\begin{array}{l}\text { End-expiratory wheezing } \\
\text { only }\end{array}$ & Expiratory wheezing & $\begin{array}{l}\text { Inspiratory and expiratory } \\
\text { wheezing or diminished breath } \\
\text { sounds }\end{array}$ \\
\hline Retractions & None & Intercostal & $\begin{array}{l}\text { Intercostal and } \\
\text { substernal }\end{array}$ & $\begin{array}{l}\text { Intercostal, substernal and } \\
\text { supraclavicular }\end{array}$ \\
\hline Dyspnoea & $\begin{array}{l}\text { Speaks in complete } \\
\text { sentences }\end{array}$ & $\begin{array}{l}\text { Speaks in short } \\
\text { sentences, coos and } \\
\text { babbles }\end{array}$ & $\begin{array}{l}\text { Speaks in partial } \\
\text { sentences, short cry }\end{array}$ & $\begin{array}{l}\text { Speaks in single words, short } \\
\text { phrases or grunting }\end{array}$ \\
\hline
\end{tabular}

vomiting, BiPAP issues, facial skin breakdown or mask related injury, PED or ward rapid responses or codes or death, any form of barotrauma from patient's radiological review, aspiration pneumonia, more advanced asthma management, extracorporeal membrane oxygenation (ECMO), and unexpected discontinuation BiPAP complications; see online supplementary material 1). Then, in 2007-2013, the BiPAP CQIP was expanded into a twophased BiPAP CQIP process. This new BiPAP CQIP format was implemented for multiple reasons: (1) to increase PED asthma BiPAP use; (2) to increase the length of PED stay due to decreasing or limited available PICU and hospital beds; and finally (3) constantly evolving patient safety analysis and feedback by the PED staff. This new BiPAP CQIP process was divided into two main parts: first phase was prospective at the bedside by a PED RT and the second stage was a retrospective EMR review after the patient left the PED. A PED RT and one of the study investigators performed the EMR review. The final BiPAP CQIP metrics are presented in online supplementary material 1. To include missed PED BiPAP patients (a process from 2005 to 2013), a biweekly PED BiPAP financial charge analysis report was reviewed by one of the primary investigators. The EMR for any of the missed PED BiPAP patients in the prospective phase was reviewed $\backslash$ and their BiPAP CQIP information was then added to the PED BiPAP CQIP REDCap by one of the investigators. The PED BiPAP CQIP key metrics were reported monthly and quarterly at the PED monthly management meetings (pediatric emergency medicine (PEM) attendings, fellows, nursing and RT) and quarterly at hospital's respiratory therapy and hospital asthma management meetings. BiPAP CQIP yearly reports were reported at the Vanderbilt Children's Hospital CQIP.
Feedback from the various meetings were implemented in the PED BiPAP QCIP and if changes were needed it was discussed at PED monthly management meetings.

In 2009-2013, a further metric revision (PED returns within 24-72 hours and any subsequent complication) to the BiPAP REDCap database was implemented for PED BiPAP ward patients with asthma who were discharged to home from the PED due to limited ward beds, and having a prolong PED stay (PED observation time $>12$ hours postadmission bed request). These ward patients were discharged home from the PED by their ward attending.

The Vision BiPAP (from 2005 to 2007) and Vision V-60 (2007 to 2013) machines (Respironics BiPAP Vision, Phillips Company, Andover, Massachusetts, USA) were the sole BiPAP delivery systems. All PED BiPAP patients with asthma had pediatric BiPAP facial masks or adjusted adult nasal or facemasks and the aerosol delivery apparatus was placed at the BiPAP facemask port. During the BiPAP collection timeframe, the initiation and discontinuation of PED BiPAP, admission to the ward or PICU, and BiPAP continuation until the patient arrived to the PICU was at the sole decision process of the PED attending physician, not following a specific BiPAP protocol or parameters. The Vision's pulmonary parameter for initial, final Inspiratory Positive Airway Pressur (IPAP), Expiratory Positive Airway Pressure (EPAP), I:E ratio settings and tidal volume (Tv; $\mathrm{mL}$ ) were recorded and placed in the PED BiPAP CQIP (see online supplementary material 1). The final Vision IPAP, EPAP, I:E ratio, TV data collection times were when the PED BiPAP was discontinued before or at 4 hours of PED BiPAP (whether discontinued or not) and PICU BiPAP length of treatment and complications (see online supplementary material 1). 
The study's asthmatic therapeutic response was defined as changes in the PAS, respiratory rate (RR), and $\mathrm{Tv}(\mathrm{mL})$ from the various PED CQIP BiPAP metric time intervals (see online supplementary material 1 ). The PED BiPAP CQIP was completely independent of the PED Asthma CQIP system.

In a significant number of patients, BiPAP was well tolerated, but there became a need for a sedative agent for patients who would become agitated on BiPAP placement. From 2005 to 2013, the PED attendings and fellows selected on ketamine as the sole sedative agent for BiPAP, after review of various agents and became a BiPAP CQIP metric. Ketamine selection was due to its bronchodilation, maintaining a gag response, airway patency and preserves the patient's respiratory drive.

Health Insurance Portability and Accountability Act (HIPAA) compliance for all aspects of patient data was maintained. A waiver of informed consent was supported by the Vanderbilt Institute for Clinical and Translational Research (UL1 TR000445 from NCATS/NIH).

\section{Statistical methods}

The paired Student's t-tests (significance level at 0.05) were applied to observe the change for $\mathrm{Tv}$, RR, IPAP and EPAP before and after BiPAP. Two mixed models with 0.05 significant level were used to compare the patient's PAS scores at initial, just before BiPAP placement, at 4 hours of BiPAP and not taken off, 4 hours and termination of PICU BiPAP or final PAS for patients admitted or discharged home, respectively. Data were analysed using SAS V.9.4 software (SAS Institute, Cary, North Carolina, USA).

\section{RESULTS}

\section{PED asthma incidence}

In 2005, based on PED EMR and acute asthma billing codes, there were 1736 patients with acute asthma out of 38500 total PED encounters; 62 (4\%) had BiPAP therapy. In 2013, there were 3612 acute asthma encounters out of 56000 PED encounters; 267 (7.3\%) patients were placed on BiPAP. From the 2005-2013 PED EMR database, there were 21798 paediatric acute asthmatics from a total PED census of 349439 over an 8-year period. A total of 1157 (5.3\%) PED moderate or severe acute asthmatics (by their PAS scores and PED EMR) had continuous bronchodilator therapy with BiPAP with $59.8 \%$ were male, median age was 4 years $(95 \%$ CI 2.3 to 6.5 ; age 9 months to 18.25 years) and median weight was $22.9 \mathrm{~kg}$ (95\% CI 15.3 to 34.3). The PED BiPAP patients had an asthma symptoms duration of 2 days (95\% CI 2 to 4$), 9.3 \%$ had fever $>38.5^{\circ} \mathrm{C}, 53 \%$ had prior PED asthma visits with $37 \%$ having a prior floor admission and $23.9 \%$ with prior PICU admissions, $8 \%$ had a prior history of asthmatic intubation (some patients had repeat intubations). From the 2005-2007 BiPAP CQIP analysis, no patient had prior PED BiPAP use. However, from 2008 to 2013, 20.6\% of these PED BiPAP patients had a prior PED asthma BiPAP experience which demonstrated an increase use and its repetitive use in certain patients. From 2005-2013 the BiPAP CQIP program did not simultaneously or subsequently record, analyze or compare to the non-BiPAP moderate to severe PED asthmatic patients.

Asthma therapy before PED BiPAP placement metric: Prior to BiPAP placement, all patients received continuous albuterol (25 mg) aerosols, and/or aerosolised epinephrine ( $3 \mathrm{mg}$ single or $6 \mathrm{mg}$ hour long) along with $87.4 \%$ of the patients received magnesium sulfate $75 \mathrm{mg} / \mathrm{kg}$ (2 $\mathrm{g}$ maximum). All PED asthmatics had a total of $2 \mathrm{mg} / \mathrm{kg}$ of steroids whether placed on BiPAP or not (from 2005 to 2008 maximum: $120 \mathrm{mg}$, 200920 013: $60 \mathrm{mg}$ ). A subcutaneous bronchodilator (epinephrine or terbutaline) was given to $24.2 \%$ of the patients during their pre-PED BiPAP placement. Isotonic fluid boluses $20 \mathrm{~mL} / \mathrm{kg}$ and IV 1.5 times maintenance fluids were given to $69.1 \%$ of the BiPAP patients. On placement of PED, BiPAP patients received $25 \mathrm{mg}$ of continuous albuterol, IV fluids, IV steroids every 6 hours (while in the PED) and no patients had systemic IV $\beta-2$ agonist therapy while on PED BiPAP.

PED BiPAP placement metrics: From 2005 to 2013, all PED patients accepted BiPAP application and therapy except for the following 13 patients who had an episode of vomiting (on average within the first $30 \mathrm{~min}$ of BiPAP placement and therapy); however, no vomiting episodes were recorded after this initial $30 \mathrm{~min}$ of BiPAP for any of the 1157 patients. Ondansetron was given prior to BiPAP placement to prevent vomiting by the PED attendings is as follows, 23.9\% of BiPAP patients received ondansetron $(0.1 \mathrm{mg} / \mathrm{kg})$ from 2005 to 2006 and from 2007 to 2013, that percentage increased to $97.8 \%$. All ondansetron dosing was the PED attending decision and became a standard practice over time. No patients had documented abdominal distension or required nasogastric $(\mathrm{N} / \mathrm{G})$ tube at any time. From 2005 to 2008, 6.1\% (20) BiPAP patients were given intermittent sedative boluses of IV ketamine $(0.5 \mathrm{mg} / \mathrm{kg})$ increasing to a total of $7.1 \%$ (82) patients from 2005 to 2013 for agitation or improve compliance with BiPAP placement and continuation. All ketamine doses were given within the first hour of the patient's BiPAP placement and with no recorded side effects: vomiting, agitation or hallucination.

The initial and subsequent changes in the PED BiPAP Vision and Vision V 60's IPAP, EPAP and I:E ratio was solely the treating PED attending in consultation with the dedicated PED RT.

A total of six patients required intubation in the PED, all occurring during 2008-2013. Five of the ketamine patients eventually required intubation after BiPAP placement (all occurring after 2011). These five intubated patients had BiPAP immediately applied in the PED as a means to prevent intubation but failed BiPAP therapy and were subsequently intubated. One PED BiPAP patient required intubation due to their inability to trigger the BiPAP circuit for breaths, $38 \mathrm{~min}$ after 
BiPAP was initiated. These intubated patients had an average initial PAS of 14 (CI 12 to 15) and their PAS just before BiPAP was 13 (95\% CI 13 to 15). BiPAP duration before intubation was $102.9 \mathrm{~min} \quad(\mathrm{SD} \pm 53.6$; range 47-270 min). These patients were intubated (using rapid sequence intubation and age-appropriate endotracheal tubes) due to worsening of their level of consciousness and/or not triggering the BiPAP circuit. There were no recorded episodes of hypoxia, bradycardia, hypotension, aspiration or barotrauma, during these PED intubations. None of the six intubated patients required an anaesthesia machine (for further relieve of their bronchospasm), or ECMO. Their mean PICU mechanical ventilation time was 28.9 hours ( $\mathrm{SD} \pm 4.3$ hours). No PICU admitted
PED BiPAP patients with continued PED BiPAP therapy or with no continued BiPAP therapy required intubation in the PICU.

A review of Vanderbilt Children's PED and PICU intubation for the 21789 PED asthma encounters (2005-2013) showed a $4.8 \%$ intubation rate. Of these $4.8 \%$ PED intubated patients with asthma, only $6(0.027 \%)$ patients had BiPAP before intubation. Of the $4.7 \%$ PED intubated asthmatics none had documented BiPAP attempts or BiPAP charges as noted in their PED EMR.

\section{PED BiPAP therapeutic and clinical metrics}

The various PED BiPAP CQI various indicators, LOS and their comparison is presented in table $2 \mathrm{~A}, \mathrm{~B}$.
Table 2 A. Patient's ped \& bipap length of time, patient's length of hospital or unit stay (los)(hours), ped bipap patient placement from 2005 to 2013 (picu, ward, ped discharge to home), number of ped bipap patients per year (picu, and total ped bipap patients)

\section{(A) Patient's PED and BiPAP length of time: ( $\mathrm{N}=1157)$ (hours)}

Time: triage to start of BiPAP: 2005-2008 (N=358)

Time: triage to start of BiPAP: 2009-2013 ( $\mathrm{N}=799)$

Time: PED LOS from admit decision to ward

Time: continuous aerosol before BiPAP start (2005-2013) (hours)

PED BiPAP patient's BiPAP duration ( $\mathrm{N}=1157)$ PED BiPAP patients with 2-

4 hours of BiPAP, BiPAP total duration $(\mathrm{N}=832)$

PED BiPAP patient's PICU BiPAP duration ( $\mathrm{N}=325)$

PED BiPAP patient's PED and PICU combined BiPAP duration ( $\mathrm{N}=325)$

PED BiPAP ward patients: average PED BiPAP duration

\section{(B) Patient's length of hospital or unit stay (LOS) (hours)}

\section{All PED BiPAP patients $(\mathrm{N}=1157)$}

PED BiPAP admitted to the PICU, total hours patients $(\mathrm{N}=325)$

PED non-BiPAP patients admitted to the PICU $(\mathrm{N}=1105)$

PED BiPAP admitted to PICU then transferred to the ward patients $(\mathrm{N}=325)$

PED non-BiPAP admitted to PICU then transferred to the ward patients $(\mathrm{N}=1105)$

PED BiPAP patients admitted to the ward with no PICU stay ( $\mathrm{N}=832)$

PED non-BiPAP patients admitted to the ward with no PICU stay $(\mathrm{N}=5031)$

Total PED duration: with $<4$ hours of BiPAP $(\mathrm{N}=832)$

PED BiPAP patients with 2-4 hours of BiPAP duration: PED admit bed request

time to the ward ( $\mathrm{N}=780$ (-52 patients below))

PED BiPAP patients with 2-4 hours of BiPAP duration: PED to home discharged observation time from end of BiPAP to home $(\mathrm{N}=52)$

\section{(C) PED BiPAP patient placement: 2005-2013}

\section{PICU}

Ward

Discharge home

(D) PED BiPAP patients per years

BiPAP, bilevel positive airway pressure; LOS, length of stay; PED, paediatric emergency department; PICU, paediatric intensive care unit.
Median (95\% Cl)
4 (3.3 to 5.1$)$
$1.53(0.45$ to 2.2$)$
10.1 (9.9 to 12.5$)$
2.35 ( 1.75 to 3.5$)$
4.3 (2.8 to 6 )
2.57 (2 to 3.5$)$
9.2 (8.4 to 13.3 )
13.7 (10.6 to 14.8$)$
3.4 (2.4 to 4.7 )

\section{Median (95\% Cl)}

41.3 (36.9,

23.7 (20.7 to 30.4 )

50.4 (48.6 to 57.6 )

46.5 (44.2 to 48.1 )

83.7 (75.8 to 94.4 )

28.2 (24.7 to 30.1 )

52.7 (44.5 to 59.7 )

10.2 (7.7 to 13.5$)$

11.9 (8.9 to 19.7$)$

13.7 (13.1 to 14.9 )

$\mathrm{N}=1157$

325

832

52

total PED

\begin{tabular}{llr}
\hline (D) PED BiPAP patients per years & $\begin{array}{c}\text { total PED } \\
\text { BiPAP patients }\end{array}$ \\
\hline 2005 & PICU admitted & 34 \\
2006 & 30 & 73 \\
2007 & 31 & 84 \\
2008 & 32 & 90 \\
2009 & 30 & 109 \\
2010 & 36 & 144 \\
2011 & 44 & 187 \\
2012 & 46 & 214 \\
2013 & 42 & 200 \\
\hline
\end{tabular}


The patients' initial $\mathrm{O}_{2}$ saturation mean was $92 \%$ (95\% CI $87 \%$ to $94 \%)$. No patients had worsening $\mathrm{O}_{2}$ saturation while on BiPAP. For the overall (2005-2013) initial to final BiPAP pulmonary settings (IPAP, EPAP,

Table 3 A. Ped bipap patient pulmonary metrics: respiratory rate, ipap, epap and tidal volume (tv) (as measured by the vision v60 bipapmachine) initial (at bipap placement) to final bipap setting. 3.b. ped bipap patient bipap pulmonary setting by age: ipap, epap (median, 95\% ci)

\begin{tabular}{lcc}
\hline $\begin{array}{l}\text { (A) BiPAP pulmonary } \\
\text { metrics (N=1157) }\end{array}$ & Initial & Final \\
\hline Respiratory rate $(\mathrm{bpm})$ & $56(46,58)$ & $26(22,31)$ \\
IPAP $(\mathrm{cm})$ & $14(12,16)$ & $18(16,24)$ \\
EPAP $(\mathrm{cm})$ & $8(6,8)$ & $8(8,8)$ \\
Tv $(\mathrm{mL})$ & $235(190,325)$ & $736(613834)$ \\
\hline (B) IPAP, EPAP by age & & \\
(years) (N=1157) & IPAP $(\mathbf{c m})$ & EPAP $(\mathbf{c m})$ \\
\hline 0-1 years $(\mathrm{N}=68)$ & $13(12,16)$ & $7(6,8)$ \\
1-2 years $(\mathrm{N}=310)$ & $16(14,16)$ & $8(7,8)$ \\
3-5 years $(\mathrm{N}=432)$ & $18(16,20)$ & $8(8,10)$ \\
6-9 years $(\mathrm{N}=213)$ & $19(17,22)$ & $8(8,10)$ \\
10-18 years $(\mathrm{N}=134)$ & $22(20,28)$ & $10(8,12)$ \\
\hline BiPAP, bilevel positive airway pressure; bpm, breaths per minute; & \\
Tv, tidal volume. & \multicolumn{2}{l}{}
\end{tabular}

Tv), RR (breaths per minute) and BiPAP setting by age is presented in table $3 \mathrm{~A}, \mathrm{~B}$. Figures 1-3 graphically demonstrate the analysis for the initial to final RR, IPAP, EPAP, $\mathrm{Tv}$ changes. The overall $(\mathrm{N}=1157) \mathrm{I}: \mathrm{E}$ median was 1.75 (95\% CI 1.5 to 1.75 ). A total of 32 obese teenage severe asthmatics ( $>97 \%$ for body mass index by weight) with their PAS median 14 (95\% CI 13 to 15 ) before BiPAP placement required IPAP settings of 26-28 $\mathrm{cm}$ for asthmatic improvement, never developed barotrauma and tolerated these high pressures extremely well. Their BiPAP duration was varied, but $35 \%$ of these patients required only 4 hours of BiPAP and never needed further BiPAP, intubation or PICU admission after BiPAP discontinuation.

In the early 2005-2007, acute asthma BiPAP therapy was started with the lower IPAP $12 \mathrm{~cm}$, EPAP $6 \mathrm{~cm}$ and I: $\mathrm{E}$ ratio 1.0. Then in 2008-2013, a trend towards increasing the baseline IPAP to $16 \mathrm{~cm}$ to a maximum of $28 \mathrm{~cm}$, EPAP 8-10 cm and an I:E ratio of 1.75 occurred.

\section{Post-PED BiPAP therapeutic response analysis}

For the PED BiPAP patient's PAS in figures 4 and 5. Of those that received BiPAP for only 2-4 hours' median was 2.7 hours (95\% CI 2 to 3.5; $\mathrm{N}=832$ ). When comparing their BiPAP PAS from just before BiPAP to PAS just before floor transfer or discharged home there was a significant PAS improvement $(\mathrm{p}<0.001)$. The PAS scores

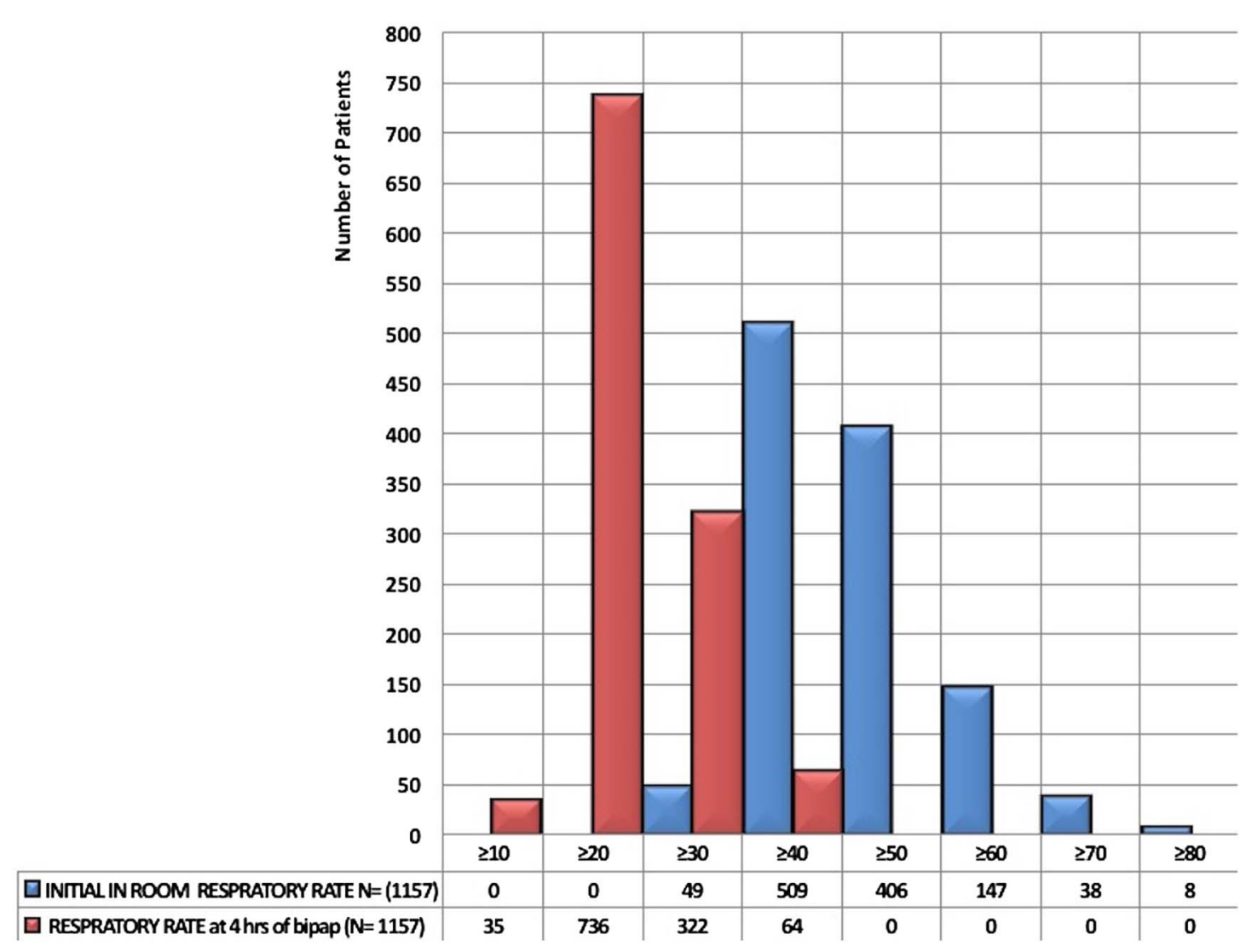

Figure 1 Initial respiratory rate bpm $(\mathrm{N}=1157)$ Respiratory rate $(\mathrm{bpm})$ fourth hour on BiPAP $(\mathrm{N}=1157) \mathrm{BiPAP}$, bilevel positive airway pressure; bpm, breaths per minute. 


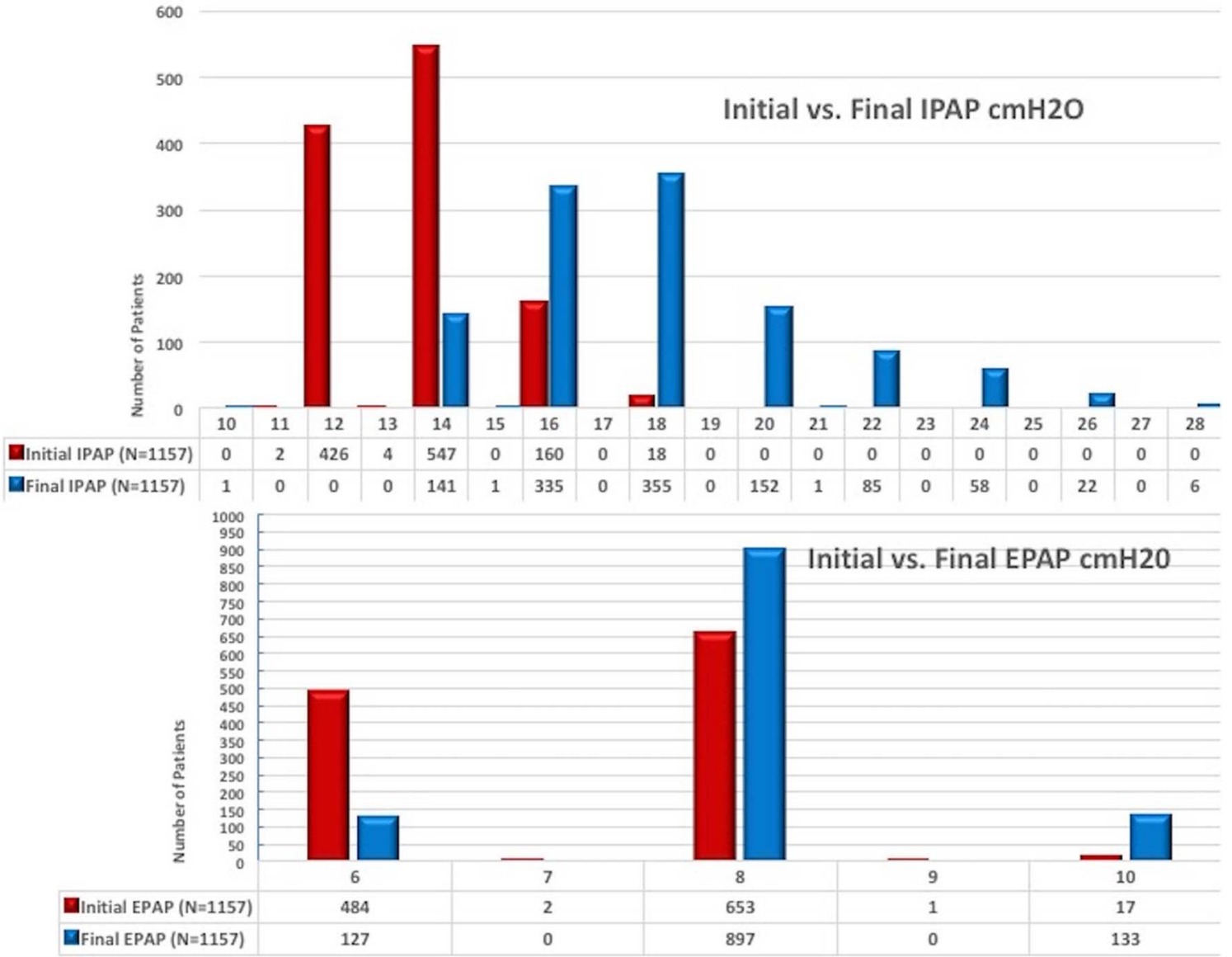

Figure 2 Initial IPAP cm H $\mathrm{H}_{2} \mathrm{O}$. Settings ( $\left.\mathrm{N}=1157\right)$; median: $14(95 \% \mathrm{Cl} 12$ to 16$) \mathrm{cm}$. Final IPAP $\mathrm{cm} \mathrm{H}_{2} \mathrm{O}(\mathrm{N}=1157)$; median: 18 $(95 \% \mathrm{Cl} 16$ to 22$) \mathrm{cm}$. Initial EPAP $\mathrm{cm} \mathrm{H}_{2} \mathrm{O}$ settings $(\mathrm{N}=1157)$; median: $8(95 \% \mathrm{Cl} 6$ to 8$) \mathrm{cm}$. Final EPAP $\mathrm{cm} \mathrm{H}_{2} \mathrm{O}(\mathrm{N}=1157)$; median: $8(95 \% \mathrm{Cl} 8$ to 8$) \mathrm{cm}$.

for PICU PED BiPAP patients with PICU BiPAP therapy $(n=325)$ continued, their PAS within $30 \mathrm{~min}$ of BiPAP placement median was 13 (95\% CI 12 to 14 ), PAS at 4 hours of PED BiPAP and with PED BiPAP continuation (just before PED transfer) was 12 (95\% CI 12 to 13 ). When comparing the PAS scores, there was a significant difference between the patient's first PAS (at the patient's PED room placement) compared with their final BiPAP PAS (BiPAP discontinuation in either the PED or PED plus PICU $(\mathrm{p}<0.001$; table $4 \mathrm{~A}-\mathrm{C})$.

\section{Post-PED BiPAP LOS and placement analysis}

Of these 1157 PED BiPAP patients from 2005 to 2013, $28 \%(\mathrm{~N}=325)$ were admitted to the PICU and $72 \%$ $(\mathrm{N}=832)$ were admitted to the ward with a trend over the years of decreasing PICU admissions (table 5). One hundred and twenty-seven $(15 \%)$ of these 832 ward patients had $<4$ hours total of BiPAP therapy with BiPAP discontinuation in the PED and had ward admission (table 4C). Owing to limited ward beds and high PED admitted patient census, some PED patients with asthma on BiPAP had an extended PED observation time from 8 to 36 hours. These patients remained in the PED while under the care of a ward-attending physician. None of the ward patients $(\mathrm{N}=780)$ had a rapid response alert or
PICU transfer. From 2009 to 2013, there were 127 ward PED BiPAP $(15.3 \%(\mathrm{~N}=832))$ patients who had 2 hours \pm 30 min of BiPAP therapy with $52(40.9 \%(\mathrm{~N}=127))$; of these, 127 patients were discharged to home with PED time from BiPAP discontinuation to PED discharge was 17.7 (95\% CI 13.8 to 23.2) hours. The discharge home decision for these 52 patients was solely the decision of the ward attending. No discharged PED BiPAP patients $(\mathrm{N}=52)$ had an asthma or non-asthma PED return visit within 72 hours post-PED discharge.

Finally, all PED BiPAP patients who had PED BiPAP discontinuation did not require further BiPAP therapy during their PED stay, PICU or ward stay. No patients had a facial skin complication or mask-related injuries, aspiration, barotrauma, pneumothorax, require $\mathrm{N} / \mathrm{G}$ tube or transfer to a higher unit/PICU, or death in the PED, ward or the PICU. None of those admitted ward, discharged or PICU patients had any subsequent complications from the BiPAP CQI analysis. Of the 1157 PED BiPAP patients, none had any BiPAP complication post 30 days or 6 months' review as part of the PED BiPAP CQIP by one of the investigators.

For the PED non-BiPAP asthmatics annual CQIP metrics showed the average number of days for the returned to the PED related to an asthma exacerbation 


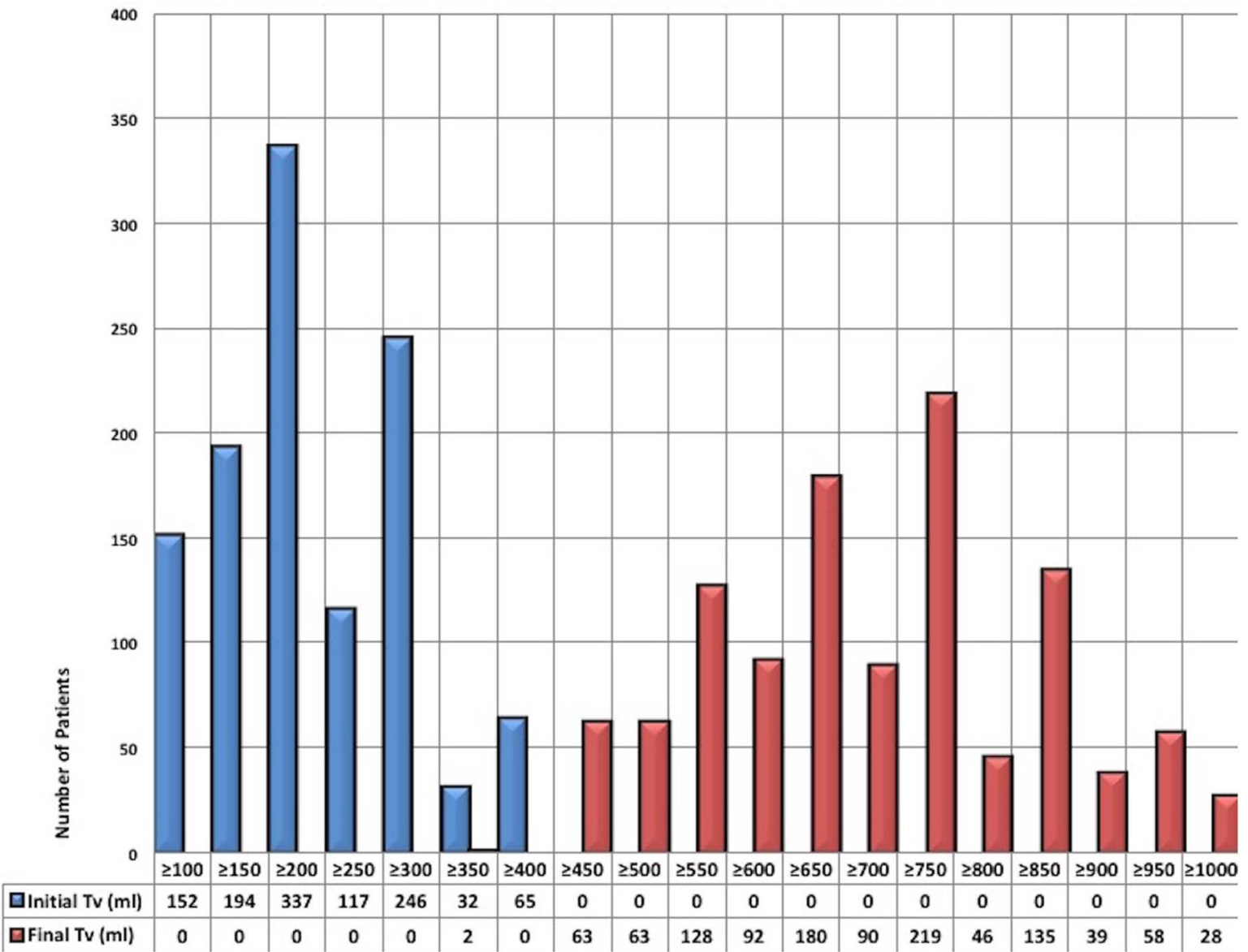

Figure 3 Initial Tv mL ( $\mathrm{N}=1157)$; median $235 \mathrm{~mL}(95 \% \mathrm{Cl} 190$ to 345). Final Tv $\mathrm{mL}(\mathrm{N}=1157)$; median $736 \mathrm{~mL}(95 \% \mathrm{Cl} 613$ to 834). Tv, tidal volume.

was 32.6 $\mathrm{SD} \pm 7.3$ days. For PED BiPAP patients, their average PED asthma exacerbation return was 123.2 SD \pm 19.4 days. The postadmission and discharge analysis showed only five of the BiPAP patients had a return to the PED $>72$ hours (median 9.1 days postdischarge (95\% CI 6.8 to 13.9)) and related to non-compliance with their asthma action plan. None of these patients had BiPAP complications or hospital admission, and all were sent home from PED during their subsequent visit.

\section{DISCUSSION}

This is the first reported longitudinal PED BiPAP CQIP with an observational analysis for paediatric patients with asthma presenting to a PED. This constantly evolving PED BiPAP CQIP has given significant clinical and therapeutic BiPAP data. Through CQIP analysis, the following BiPAP trends occurred: (1) increased BiPAP therapy acceptance and use, (2) BiPAP was initiated earlier in the asthma therapy when comparing years, and (3) increased earlier BiPAP use as a bridge to avoid intubation. The intubation rate increased during the 2009-2013 timeframe as compared with 2005-2008. This probably relates to a quicker BiPAP application in those who would have had intubation without the BiPAP intervention. The BiPAP CQIP demonstrated that the attending physicians were more willing to initiate BiPAP therapy as a possible bridge to prevent intubation in these patients with asthma with respiratory failure and probably due to a very limited PICU bed availability. This could also be a significant contributing factor resulting in greater BiPAP incidence and success.

This BiPAP CQIP produced constant feedback and practice style dissemination to the faculty and staff about complications, benefits and changes in BiPAP pressure setting. This was likely a key component in the overall acceptance of BiPAP use. By actively participating in this process, PED providers witnessed the benefits of the programme, and were given the opportunity to adopt this therapeutic modality. The increased PED BiPAP usage in this study could also be related to the following: (1) observation of its ease-of-use and excellent patient tolerance, especially in very young children, (2) significant clinical improvement for patients with asthma, (3) debunking complication myths, (4) improved technical and application skills, and (5) a constantly evolving PED BiPAP CQI.

From early aged to preadult patients, PED BiPAP did significantly improve their acute asthma (PAS) severity score, improve their asthmatic pulmonary parameters, 


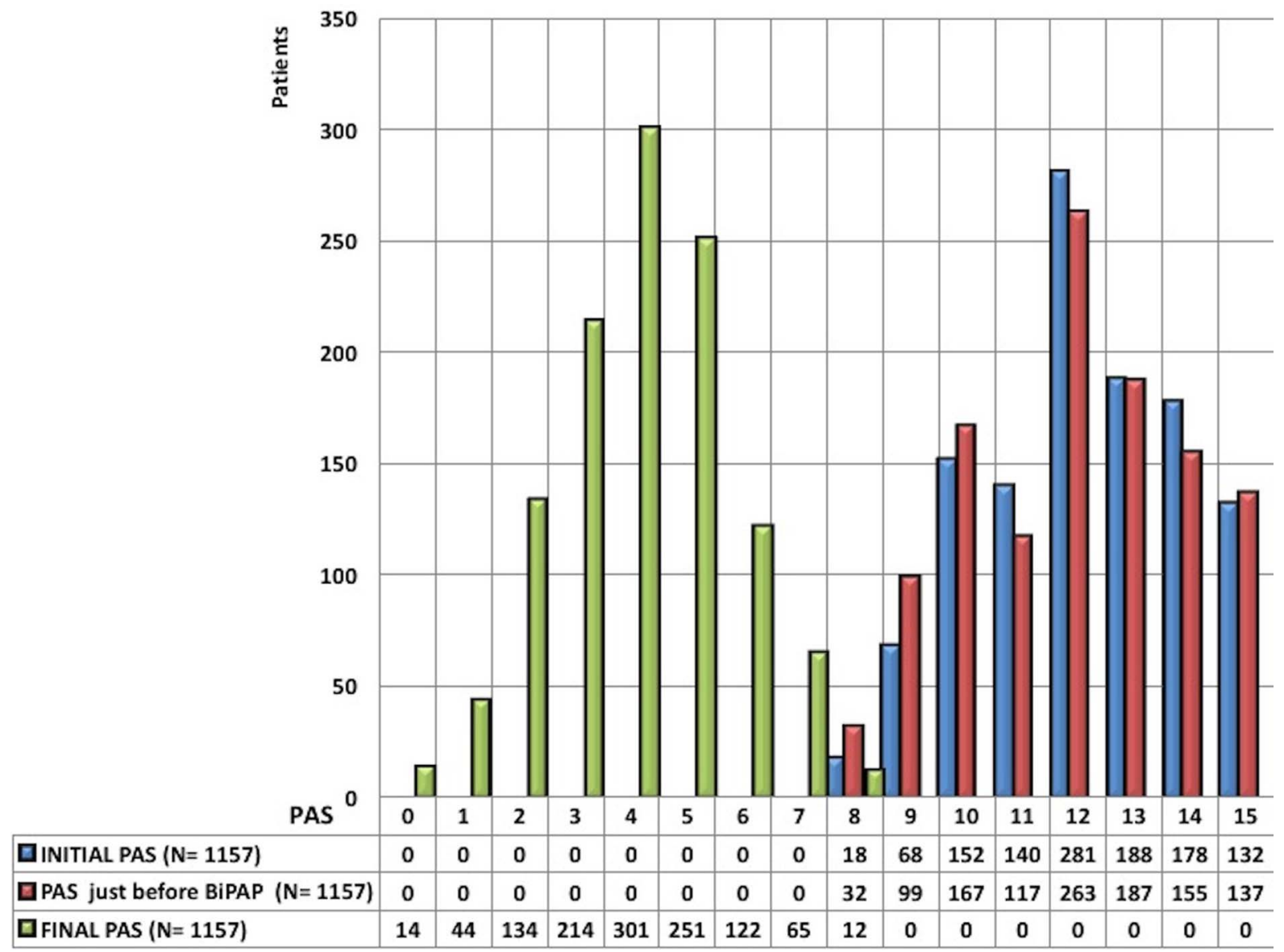

Figure 4 All BiPAP patients PAS score (mild=PAS score 0-7, moderate=PAS score 8-11, severe=PAS score 12-15; N=1157). Patient's PAS measurement times. BiPAP, bilevel positive airway pressure; PAS, Pediatric Asthma Severity.

decrease PICU admission, decrease intubation rates and all without complications. These PED BiPAP asthmatics also showed their intubation occurrences were significantly lower than the non-BiPAP patient population and the national trend. ${ }^{15-21}$ As none of these 1157 patients had any complications, from this large BiPAP CQIP, it has disproven the supposed BiPAP risks in the acute paediatric patient with asthma. This large patient volume has shown no vomiting occurrence after $30 \mathrm{~min}$ of BiPAP application (especially after instituting IV ondansetron before or during BiPAP placement) and no abdominal distention nor required a N/G tube, disproving that BiPAP causes abdominal distention secondary to increased gas delivered to the gastrointestinal tract and requires a N/G tube. This CQIP analysis showed that it was well tolerated by all age ranges with younger asthmatics, in particular, required minimal to no sedation. From the BiPAP CQIP 2008-2013 analysis, trends showed an increasing occurrence of patients requiring only 2-4 hours of BiPAP therapy, and an increase BiPAP use in non-responsive moderate asthmatics. The causative factors for the longer PED asthma return rate for these PED BiPAP patients compared with the non-PED BiPAP asthmatic was not a BiPAP CIPQ metric but warrants further investigation.
A small PED BiPAP patient group required ketamine on the placement of BiPAP. An increase ketamine use occurred in the later years probably related to the earlier BiPAP application in these severe asthmatics in respiratory failure per the EMR PED attending's documentation and feedback comments. In clinical practice, relieving the agitation of the patient with asthma during BiPAP placement has not been studied, but it is a practice management style. ${ }^{21-26}$

The paediatric asthmatic BiPAP settings (IPAP, EPAP, I: E ratio) literature is sparse. ${ }^{13-15}$ 19-30 This BiPAP CQIP demonstrated at a higher IPAP, lower EPAP and a longer I:E ratio, comparing their asthma severity, there was a quicker therapeutic response as defined by quicker improvement in PAS, RR and improved Tv. These changes produced a significant decrease in RR, retractions and increase in final $\mathrm{Tv}$ compared with initial Tv during the 4 hours of BiPAP duration. These BiPAP settings probably alleviated the airway obstruction producing less work of breathing, better airway bronchodilator deposition and faster asthma attack resolution as shown by the patients reduced therapeutic times. ${ }^{13-15}{ }^{19-31}$ In the acute asthma attack, the difference is the inspiratory air flow is dependent on the areas of lung obstruction and the severity of obstructed airway as the key factor in 


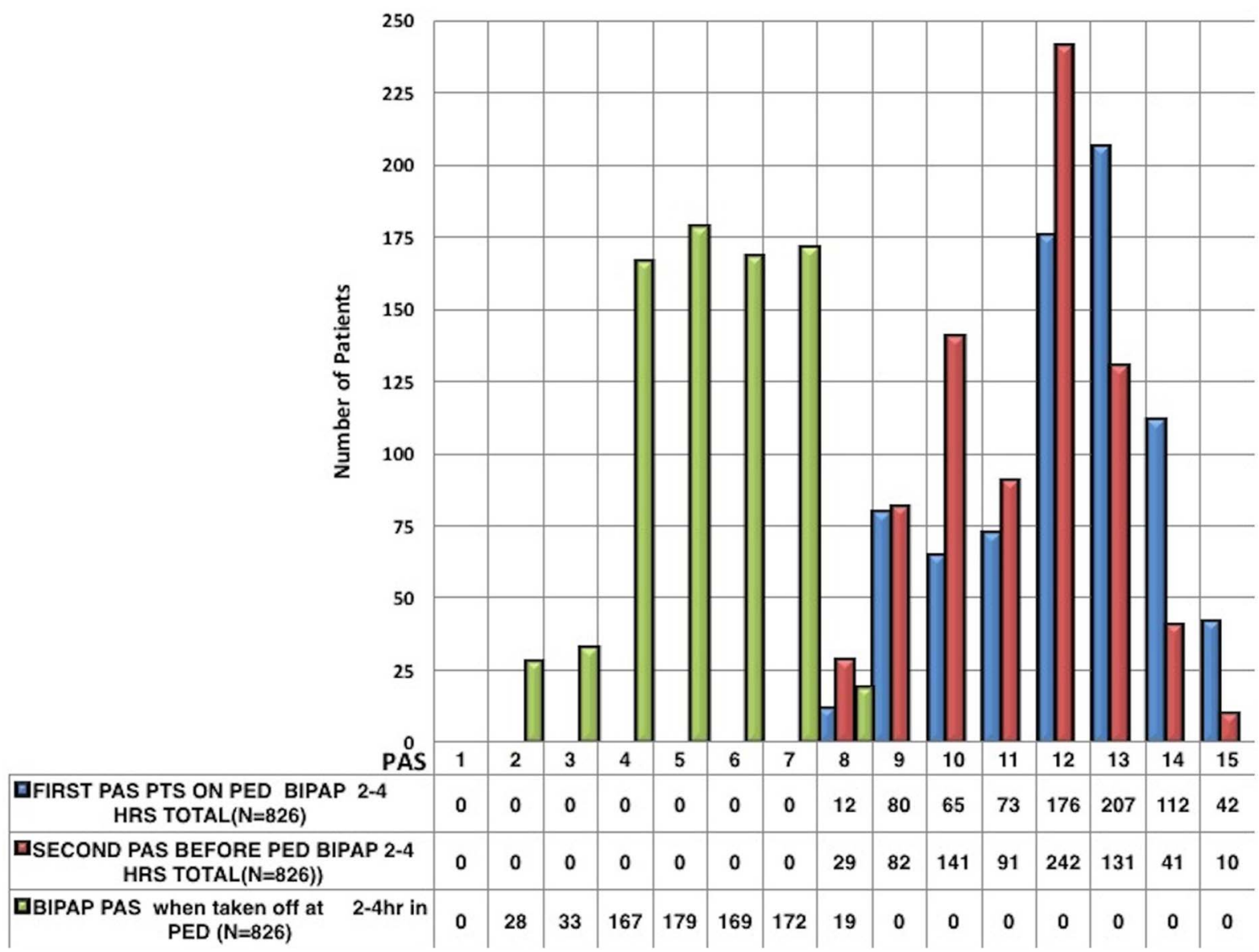

Figure 5 Patients with only 2-4 hours of PED BiPAP: PAS score (mild=PAS score 0-7, moderate=PAS score 8-11, severe=PAS score 12-15; $\mathrm{N}=832$ ). Patient's PAS measurement times. BiPAP, bilevel positive airway pressure; PAS, Pediatric Asthma Severity; PED, paediatric emergency department.

nebulisation deposition causing the varied clinical improvement. ${ }^{19-31}$ These above factors may contribute to this airway heterogeneity, especially the bronchodilator therapy response in the moderate-to-severe acute asthmatic. $^{7-9}$ 21-31 BiPAP opens the obstructed airway or allows limited flow, and it improves aerosol deposition. ${ }^{19} 2022-31$ Using BiPAP could improve drug deposition, and improve patients' respiratory status regardless of the patient's specific airway heterogeneity, variable drug response ( $\beta-2$ receptors) and variable airway closure. $^{20-23}$ 26-31 This CQIP analysis demonstrates the resolution of these possible factors through decreased PAS scores, lower RRs and improved Tv. These findings could relate to the greater inspiratory flow pressure and longer inspiratory time effect on the variable airway obstruction, causing better bronchodilator deposition. $^{10} 13192022-26283031$ Recent adult BiPAP studies have supported the clinical experience of gradually increasing the patient's IPAP in relationship to their work of breathing and RR, which leads to significant decrease in work of breathing and RR. ${ }^{10-13}{ }^{19-}$ 2326283031 When the patient achieved IPAP plateau, their work of breathing (accessory respiratory muscles $\mathrm{RR}$ and retractions) significantly decreased and $\mathrm{TV}$ increased. ${ }^{19-23} 26283031$ This CQIP analysis has shown similar findings. Also increasing the patient's inspiratory breath time produces a longer airway distension time on the obstructed airways causing an improvement in airflow and ventilation. ${ }^{21} 22$ 24-31 From this large patient population these new practice BiPAP settings could be physiologically causing a reduction in the severe airway trapping and hyperventilation, improved airflow decreasing intrinsic PEEP and increased in the patient's inspiratory capacity. ${ }^{21} 22$ 24-31 This warrants further investigation.

A current misperception by emergency medicine (EM) and PICU physicians pertains to using BiPAP in asthmatics which will increase the patient's auto-PEEP level causing greater incidences of respiratory failure and intubations. $^{21} 22$ 24-31 This large PED BiPAP population showed more of a reversal of this auto-PEEP tenet when using BiPAP. During acute bronchospastic episodes, children have an increase in airway resistance, causing increased workload for inspiratory air movement into the lungs and prolonged expiratory phase due to air trapping and decreased expiratory ventilatory flow level. ${ }^{21} 22$ 24-

${ }^{31}$ The combination of these prolonged time constants and the premature closure of inflamed airways during exhalation leads to dynamic hyperinflation/air trapping causing an increased auto-PEEP at the alveolar 
Table 4 PED BiPAP Patient's Pediatric Asthma Scores Comparison Analysis for all patients, PICU patients, Non-PICU (Ward) patients, Ward with discharge to home: PAS score at triage, PAS just before BiPAP placement, at 2 or 4 hours of total BiPAP duration, PAS Final- at time of BiPAP discontinuation, and 30 minutes before patient transfer or discharge home. Comparison analysis between the various PAS times for all PED BiPAP patients and their disposition (median, 95\% Cl, P value)

\begin{tabular}{|c|c|c|c|}
\hline (A) All PED BiPAP patients $\mathrm{N}=1157$ & $\begin{array}{l}\text { PAS } \\
\text { Median } \\
(95 \% \mathrm{Cl})\end{array}$ & $\begin{array}{l}\text { BiPAP non-PICU: total } \\
\text { BiPAP } \\
\text { Duration of }<4 \text { hours, } \\
\mathrm{N}=832\end{array}$ & $\begin{array}{l}\text { PAS } \\
\text { Median } \\
(95 \% \mathrm{CI})\end{array}$ \\
\hline Just before start of BiPAP PAS & $12(11$ to 14$)$ & $\begin{array}{l}\text { Just before start of } \\
\text { BiPAP PAS }\end{array}$ & $12(11$ to 14$)$ \\
\hline Initial PAS & $13(12$ to 14$)$ & Initial PAS & $13(12$ to 14$)$ \\
\hline Final PAS off BiPAP & $4(4$ to 6$)$ & Final PAS off BiPAP & $4(4$ to 5$)$ \\
\hline $\begin{array}{l}\text { (B) Only PED BiPAP non-PICU patients with } \leq 4 \text { hours total } \\
\text { BiPAP duration, } N=832\end{array}$ & $\begin{array}{l}\text { Differences } \\
\text { Median }(95 \% \mathrm{Cl})\end{array}$ & p Value & \\
\hline $\begin{array}{l}\text { Just before BiPAP start PAS-final PAS off BiPAP } \\
\text { Initial PAS-final PAS off BiPAP } \\
\text { Initial PAS-just before BiPAP start }\end{array}$ & $\begin{array}{l}6.0(5.8 \text { to } 6.1) \\
6.8(6.7 \text { to } 7.0) \\
0.9(0.7 \text { to } 1.0)\end{array}$ & $\begin{array}{l}<0.001 \\
<0.001 \\
<0.001\end{array}$ & \\
\hline All PED BiPAP patients: PICU, ward and home, N=1157 & Differences & p Value & \\
\hline $\begin{array}{l}\text { Just before BiPAP start PAS-final PAS off BiPAP } \\
\text { Initial PAS-final PAS off BiPAP } \\
\text { Initial PAS-just before BiPAP start }\end{array}$ & $\begin{array}{l}8.0(7.8 \text { to } 8.1) \\
8.1(8.0 \text { to } 8.3) \\
0.2(0.03 \text { to } 0.29)\end{array}$ & $\begin{array}{l}<0.001 \\
<0.001 \\
0.01\end{array}$ & \\
\hline (C) PICU PED BiPAP patients PAS, N=325 & Median $(95 \% \mathrm{Cl})$ & & \\
\hline $\begin{array}{l}\text { Initial PAS } \\
\text { PAS AT } 4 \text { hours of PED BiPAP } \\
\text { PAS at when BiPAP taken off }\end{array}$ & $\begin{array}{l}13(12 \text { to } 15) \\
11(10 \text { to } 13) \\
5(4 \text { to } 6)\end{array}$ & & \\
\hline PICU PED BiPAP patients PAS, N=325 & Differences & p Value & \\
\hline PICU_-initial-final PAS off BiPAP & $8.2(6.7$ to 8.3$)$ & $<0.001$ & \\
\hline $\begin{array}{l}\text { (D) Patients with } 2 \text { hours of PED BiPAP therapy: } \\
\text { PAS }(\mathrm{N}=127)\end{array}$ & $\begin{array}{l}\text { PAS median } \\
(95 \% \mathrm{Cl})\end{array}$ & & \\
\hline $\begin{array}{l}\text { Initial PAS } \\
\text { Just before BiPAP start PAS } \\
\text { PED BiPAP PAS } 30 \text { min before transfer to PICU } \\
\text { Final PAS off BiPAP ( } 30 \text { min after BiPAP stoppage) }\end{array}$ & $\begin{array}{l}12(11 \text { to } 14) \\
13(12 \text { to } 15) \\
11(10 \text { to } 13) \\
4(3 \text { to } 5)\end{array}$ & & \\
\hline (E) PED BiPAP patients discharge to home $(\mathrm{N}=52)$ & $\begin{array}{l}\text { PAS median } \\
(95 \% \mathrm{Cl})\end{array}$ & & \\
\hline Initial PAS & $12(10$ to 14$)$ & & \\
\hline Just before BiPAP start PAS & $12(11$ to 13$)$ & & \\
\hline Final PAS off BiPAP (30 min after BiPAP stoppage) & $5(4$ to 6$)$ & & \\
\hline Discharge home PAS 30 min before discharge & 3 (3 to 5$)$ & & \\
\hline BiPAP patients discharge to home $(\mathrm{N}=52)$ : time from PED & $17.7(13.8$ to & & \\
\hline BiPAP stoppage to home (hours) & 23.2) & & \\
\hline
\end{tabular}

level. $^{21} 22$ 24-31 This increased inspiratory load effect on the initiation of a breath requires a reduction in the alveolar pressure to subatmospheric levels and results in greater inspiratory work with respiratory muscle fatigue over time. BiPAP provides breath-activated inspiratory pressure support to open the obstructed airways, thus reducing the change in alveolar pressure needed to initiate inspiration. ${ }^{4-11}$ 21-24 26 28-31 BiPAP reduces inspiratory work of breathing by maintaining patency of smaller airways and offsetting auto-PEEP. ${ }^{21-24} 26$ 28-31 Also, the inspiratory pressure provided via BiPAP helps to support fatigued respiratory muscles and raise Tvs, thus improving dyspnoea and gas exchange. ${ }^{21-24} 26$ 28-31 BiPAP can also provide a continuous expiratory pressure that maintains small airway patency, thus improving the expiratory ventilatory flow, causing decreased hyperinflation. ${ }^{21-}$ 2426 28-31 From these PED BiPAP patient's data analysis, this expected increase in auto-PEEP due to BiPAP use did 
Table 5 PED BiPAP patient placement: 2005-2013

\begin{tabular}{lll}
\hline & $\mathbf{N}=\mathbf{1 1 5 7}$ & \\
\hline PICU & 325 & \\
Ward & 832 & \\
Discharge home & 52 & \\
PED BiPAP patients & PICU & Total PED BiPAP \\
per years & admitted & patients \\
2005 & 34 & 54 \\
2006 & 30 & 73 \\
2007 & 31 & 84 \\
2008 & 32 & 90 \\
2009 & 30 & 109 \\
2010 & 36 & 144 \\
2011 & 44 & 187 \\
2012 & 46 & 214 \\
2013 & 42 & 200
\end{tabular}

BiPAP, bilevel positive airway pressure; PED, paediatric emergency department; PICU, paediatric intensive care unit.

not occur as reflected by significant decreases in RR, decreases in PAS, increases in Tv and very low intubation rate. ${ }^{21-24} 2628-31$

In summary, from this large patient experience and CQIP analysis, increasing the IPAP while keeping low EPAP and increasing the inspiratory time had a significant effect on increasing Tvs, decreasing RR, retractions and PAS scores with less BiPAP therapy duration but further study is warranted. These findings are very similar to the adult BiPAP studies of higher IPAP and prolonging I:E, which also showed significant improvement in therapeutic response times, and pulmonary function tests. ${ }^{23-31}$ Overall this BiPAP CQIP analysis has showed in these PED BiPAP patients once they have accepted the BiPAP application, the PED clinical practice trend of increasing the IPAP (specific IPAP plateau, EPAP and I:E ratio), increasing inspiratory time and not the EPAP probably produced the greatest clinical effects and faster therapeutic response time as defined by a significant work of breathing reduction, reduction in retraction and $R R$ and with an increase in $T v$.

There is a paradigm shift to linking $\beta-2$ agonist therapy with an increase inspiratory pressure support to distend the obstructed airway lumen, relieve inspiratory work of breathing and improve bronchodilator deposition in the adult ED asthmatic therapeutic regimen. In recent paediatric asthmatic studies, the notion of ventilation heterogeneity and individualistic $\beta-2$ receptor response to medications has been proposed as the cause of the patient's variation to bronchodilators response and nebulisation management. ${ }^{7-9}$ 28-30 This BiPAP CQIP demonstrated in paediatric asthmatics by incorporating a distended increased inspiratory airway pressure with aerosolisation delivery, it probably alleviated the collapsed or obstructed airways, improved the bronchodilator deposition and ventilation while being safe. ${ }^{7-9} 26$ 28-31 As previously stated, using these PED BiPAP IPAP, EPAP, I: $\mathrm{E}$ settings, this large patient population did not experience any complications, increased intubation rates or PICU admissions nor any BiPAP-related returns to the PED. Our findings are similar to the adult BiPAP literature.

\section{Limitations}

This study is not a BiPAP RCT study but continuous quality improvement programme process over an 8-year period. Its intention was not a comparison between non-BiPAP to the BiPAP patients, due to numerous inherent biases: attending practice variation following the typical 'Technology Adoption Life Cycle', PICU bed availability effecting management style ergo more aggressive asthma management, long PED BiPAP duration times due to limited bed availability, PED staffs improved BiPAP therapy comfort level, attending preference in using BiPAP earlier for various reasons. Also, while comparing the time periods PED BiPAP 2005-2007 to 20082013 patients, the latter has significant attending bias due to changing BiPAP experience. With the use of ondansetron and ketamine in the our PED BiPAP, the incidence with the potential complication for vomiting, aspiration and BiPAP failure probably had an effect on these complication potential occurrences.

\section{CONCLUSION}

This 8-year PED BiPAP asthmatic CQIP analysis showed overwhelming patient compliance, no complications, improved pulmonary ventilation and therapeutic response time. PED BiPAP in asthmatics did not increase intubation occurrence. This BiPAP CQIP demonstrated clinically that by using higher IPAP, lower EPAP and longer I:E of 1:75, there was a significant reduction in $\mathrm{RR}$ and asthma scores, increased $\mathrm{Tv}$, and positively affected patient dispositions. This aspect warrants further investigation. BiPAP should be considered early in the patient with severe asthma and is safe and effective. In the PED moderate asthmatics, who need further therapy or potential PICU criteria, a BiPAP trial has shown significant PICU admission reduction and no complications.

\section{Author affiliations}

${ }^{1}$ Division of Pediatric Emergency, Department of Pediatrics, Vanderbilt School of Medicine

${ }^{2}$ Division of Pediatric Emergency Medicine, Department of Pediatrics, University of Arkansas School of Medicine Arkansas Children's Hospital Little Rock, Little Rock, Arkansas, USA

${ }^{3}$ Vanderbilt School of Medicine, Nashville, Tennessee, USA

${ }^{4}$ Pediatric Emergency Medicine Associates of Atlanta, Atlanta, Georgia, USA ${ }^{5}$ University of Texas Southwestern Medical Center

${ }^{6}$ University of Tennessee LeBonheur Children's Hospital Memphis Tennessee ${ }^{7}$ Department of Respiratory Care, Vanderbilt Medical University, Vanderbilt Children's Hospital

${ }^{8}$ Department of Pediatrics, University of Arkansas School of Medicine ${ }^{9}$ Department of Pediatric Emergency Medicine, Respiratory Care, Arkansas Children's Hospital

Acknowledgements The authors would like to acknowledge Suzanne Godbold RT for her graphical support (beside involvement in the manuscript preparation, review and comments) for producing the graphic slides; Melissa 
Moore for her proof reading and preparation for the manuscript submission. The authors would also like to acknowledge Dr Nick's excellent statistical expertise, wisdom and tenacity with this manuscript. Dr Nick passed away recently and will surely be missed by all his colleagues and friends.

Contributors TA and CBJ were the original designer and architect for the PED BiPAP CQIP. They were the primary investigators for developing the biweekly data report from the PED financial charges for BiPAP therapy to detect patients. TA and CBJ were the primary people who developed the handwritten BiPAP data sheet and collected the CQIP data metrics from the PED BiPAP patient's EMR from 2005 to 2007. From 2007 to 2013 AW, SM, along with TA became the primary investigators for retrieving the bedside data sheet, patient EMR, BiPAP CQIP metrics analysis and implementing this data into REDCap database. TA was a primary recipient for the automatic PED BiPAP data inquiry, which was generated every 2 weeks for patients who had financial charges for BiPAP ventilation. MM and $\mathrm{KC}$ were active participants in this study by facilitating the supporting data collection at the bedside, ensuring that the datasheets were collected at the bedside and most importantly facilitated in the BiPAP CQIP continuation through the years. They were also very instrumental in the write up of the manuscript in all aspects from conception to completion. $\mathrm{TA}$, AW and MM were the main authors for the manuscript, figures and tables. $\mathrm{KC}$ and RS were actively involved in the manuscript revisions and edits. TN and $\mathrm{ZH}$ did all the statistical analyses for the BiPAP CQIP data.

Funding This research received no specific grant from any funding agency in the public, commercial or not-for-profit sectors.

Competing interests None declared.

Ethics approval The Vanderbilt Medical University IRB approved this CQIP review study.

Provenance and peer review Not commissioned; externally peer reviewed.

Data sharing statement No additional data are available.

Open Access This is an Open Access article distributed in accordance with the Creative Commons Attribution Non Commercial (CC BY-NC 4.0) license, which permits others to distribute, remix, adapt, build upon this work noncommercially, and license their derivative works on different terms, provided the original work is properly cited and the use is non-commercial. See: http:// creativecommons.org/licenses/by-nc/4.0/

\section{REFERENCES}

1. Newth CJ, Meert KL, Clark AE, et al. Fatal and near-fatal asthma in children: the critical care perspective. J Pediatr 2012;161:214-21.

2. Nelson KA, Zorc JJ. Asthma update. Pediatr Clin North Am 2013;60:1035-48.

3. Rogers L, Reibman J. Pharmacologic approaches to life-threatening asthma. Ther Adv Respir Dis 2011;5:397-408.

4. Martin JG, Shore SA, Engel LA. Mechanical load and inspiratory muscle action during induced asthma. Am Rev Respir Dis 1983;128:455-60

5. Golden C, Xu M, Estrada C, et al. Clinical outcomes after bilevel positive airway pressure treatment for acute asthma exacerbations. JAMA Pediatr 2015;169:186-8.

6. Rodrigo GJ, Rodrigo C, Hall JB. Acute asthma in adults: a review. Chest 2004;125:1081-102.

7. Carrol CL, Stolzt P, Schramm CM, et al. Beta 2 adrenergic receptor polymorphisms affect response to treatment in children with severe asthma exacerbations. Chest 2009;135:1186-92.

8. Hizawa N. Pharmacogenetics of $\beta 2$-agonists. Allergol Int 2011;60:239-46.

9. Teague WG, Tustison NJ, Altes TA. Ventilation heterogeneity in asthma. J Asthma 2014:51:677-84.

10. Dexheimer JW, Abramo TJ, Arnold DH, et al. Implementation and evaluation of an integrated computerized asthma management system in a pediatric emergency department: a randomized clinical trial. Int J Med Inform 2014;83:805-13.

11. Aldrich TK, Hendler JM, Vizioli LD, et al. Intrinsic positive end expiratory pressure in ambulatory patients with airways obstruction. Am Rev Respir Dis 1993;147:845-9.

12. Shirivam U, Donath J, Khan FA, et al. Effects of continuous positive airway pressure in acute asthma. Respiration 1987;52:157-62.

13. Oddo M, Feihl F, Schaller MD, et al. Management of mechanical ventilation in acute severe asthma: practical aspects. Intensive Care Med 2006;32:501-10.

14. Carrera M, Marın JM, Antoachn A, et al. A controlled trial of noninvasive ventilation for chronic obstructive pulmonary disease exacerbations. J Crit Care 2009;24:473.e7-e14.

15. Keenan SP, Gregor J, Sibbald WJ, et al. Noninvasive positive pressure ventilation in the setting of severe, acute exacerbations of chronic obstructive pulmonary disease: more effective and less expensive. Crit Care Med 2000;28:2094-102.

16. Keenan SP, Powers CE, McCormack DG. Noninvasive positive pressure ventilation in patients with milder chronic obstructive pulmonary disease exacerbations: a randomized controlled trial. Respir Care 2005;50:610-16.

17. Soroksky A, Klinowski E, llgyev E, et al. Noninvasive positive pressure ventilation in acute asthmatic attack. Eur Respir Rev 2010;19:39-45.

18. Beers SL, Abramo TJ, Bracken A, et al. Bilevel positive airway pressure in the treatment of status asthmaticus in pediatrics. Am J Emerg Med 2007;25:6-9.

19. Williams A, Abramo TJ, Shah MV, et al. Safety and clinical findings of BiPAP utilization in children $20 \mathrm{kr}$ or less for asthma exacerbations. Intensive Care Med 2011;37:1338-43.

20. Carroll CL, Zucker AR. Barotrauma not related to type of positive pressure ventilation during severe asthma exacerbations in children. $J$ Asthma 2008;45:421-4.

21. Roberts J, Bratton S, Brogan T. Acute severe asthma: differences in therapies and outcomes among pediatric intensive care units. Crit Care Med 2002;30:581-3.

22. Franca EE, Dornelas de Andrade AF, Cabral G, et al. Nebulization associated with bi-level noninvasive ventilation: analysis of pulmonary radioaerosol deposition. Respir Med 2006;100:721-8.

23. Tassaux D, Gainnier M, Battisti A, et al. Impact of expiratory trigge setting on delayed cycling and inspiratory muscle workload. Am J Respir Crit Care Med 2005;172:1283-9.

24. Chiumello D, Polli F, Tallarini F, et al. Effect of different cycling-off criteria and positive end-expiratory pressure during pressure support ventilation in patients with chronic obstructive pulmonary disease. Crit Care Med 2007;35:2547-52.

25. Galindo-Filho VC, Dornelas-de-Andrade A, Brandão DC, et al. Noninvasive ventilation coupled with nebulization during asthma crises: a randomized controlled trial. Respir Care 2013;58:241-9.

26. Brandao DC, Lima VM, Filho VG, et al. Reversal of bronchial obstruction with bi-level positive airway pressure and nebulization in patients with acute asthma. J Asthma 2009;46:356-61.

27. Mukhopadhyay A, Dela Pena E, Wadden B, et al. Effects of inhalational bronchodilator treatment during noninvasive ventilation in severe chronic obstructive pulmonary disease exacerbations. $J$ Crit Care 2009;24:474. e471-e475.

28. Soma $\mathrm{T}$, Hino $\mathrm{M}$, Kida $\mathrm{K}$, et al. A prospective and randomized study for improvement of acute asthma by non-invasive positive pressure ventilation (NPPV). Intern Med 2008:47:493-501.

29. Basnet S, Mander G, Andoh J, et al. Safety, efficacy, and tolerability of early initiation of noninvasive positive pressure ventilation in pediatric patients admitted with status asthmaticus: a pilot study. Pediatr Crit Care Med 2012;13:393-8.

30. Carroll CL, Schramm CM. Noninvasive positive pressure ventilation for the treatment of status asthmaticus in children. Ann Allergy Asthma Immunol 2006;96:454-9.

31. Leatherman JW, McArthur C, Shapiro RS. Effect of prolongation of expiratory time on dynamic hyperinflation in mechanically ventilated patients with severe asthma. Crit Care Med 2004;32:71542-5. 